\title{
SMOS CP34 soil moisture and ocean salinity maps
}

\author{
J. Font, C. Gabarró, J. Ballabrera, A. Turiel, J. \\ Martínez, M. Umbert, F. Pérez, N. Hoareau, M. \\ Portabella, V. González, J. Gourrion, S. Guimbard \\ ICM/UTM, CSIC, Barcelona, Spain \\ SMOS Barcelona Expert Centre \\ jfont@icm.csic.es
}

\author{
M. Piles, A. Camps, M. Vall-llossera \\ Remote Sensing Laboratory, Universitat Politècnica de \\ Catalunya, Barcelona, Spain \\ SMOS Barcelona Expert Centre
}

\begin{abstract}
This paper presents the soil moisture and ocean salinity maps from the SMOS mission generated operationally by the Spanish SMOS Level 3 and 4 data processing center (CP34) and experimentally by the SMOS Barcelona Expert Center (SMOS-BEC).
\end{abstract}

Keywords-SMOS mission; soil moisture; ocean salinity; level 3 and 4 products; CP34; SMOS-BEC

\section{INTRODUCTION}

The European Space Agency's Soil Moisture and Ocean Salinity (SMOS) mission was launched on November 2009 and entered into operations phase in May 2010. SMOS provides global coverage of the Earth's surface Ocean Salinity (OS) and Soil Moisture (SM) every 3 days with a spatial resolution of $40-50 \mathrm{~km}$ and an adequate accuracy for climatologic and large scale studies. SMOS carries the Microwave Imaging Radiometer using Aperture Synthesis (MIRAS), a novel 2D interferometer with 69 antennas distributed over a Y-shaped array and operating at $1.4 \mathrm{GHz}$. It is an explorer mission with the goal of demonstrating the feasibility of this novel interferometric technology to provide for the first time from space these two key geophysical variables to understand the global water cycle in our planet $[1,2]$.

The ESA mandate covers until the generation and distribution of level 2 (L2) products, namely soil moisture and ocean salinity values in an ISEA4H9 grid (15 km triangular mesh size) covering the SMOS swath along semi-orbits. Both France and Spain provided additional contributions to the development and implementation of the mission, including the establishment of high level SMOS data processing systems (CATDS and CP34, respectively) to deliver elaborated level 3 (L3, global gridded maps) and level 4 (L4, SMOS data integrated with information from other sources) products of interest to the international research community.

\section{CP34 PDC AND SMOS-BEC}

\section{A. The Spanish SMOS Level 3 and 4 Center}

The Centro de Producción de datos SMOS de niveles 3 y 4 (CP34) was funded by the Spanish Research and Development National Plan from 2004 through a series of research grants managed by the Institut de Ciències del Mar (ICM), Marine Sciences Institute from the Consejo Superior de
Investigaciones Cientificas (CSIC), Spanish Research Council (MIDAS projects).

The CP34 is composed of a Production and Distribution Centre (PDC) and an Expert Centre (EC) in charge of designing and validating the processing algorithms. The CP34PDC is installed in the European Space Astronomy Centre (ESAC) in Villanueva de la Cañada, near Madrid, Spain, side by side with the SMOS ESA's Data Processing Ground Segment (DPGS) that generates the L1 and L2 products. At present CP34 is operationally serving different types of soil moisture and ocean salinity L3 maps using different time and space windows and map generation methodologies (see http://www.cp34-smos.icm.csic.es/ for details). Research users interested in downloading or receiving these maps can register at http://www.cp34-users.cmima.csic.es/.

\section{B. The SMOS Barcelona Expert Center}

The role of CP34-EC is taken by the SMOS Barcelona Expert Centre on Radiometric Calibration and Ocean Salinity (SMOS-BEC, http://www.smos-bec.icm.csic.es/). The SMOSBEC is a joint initiative of the CSIC and the Universitat Politècnica de Catalunya (UPC). It was established in 2007 and is formed by scientists, engineers, technicians and $\mathrm{PhD}$ students from both institutions involved in SMOS activities.

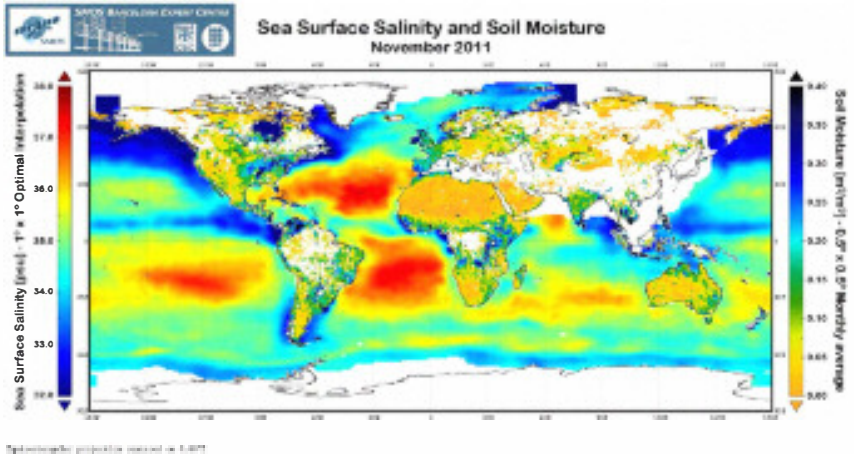

Figure 1. Global monthly soil moisture and ocean salinity experimental map (November 2011) built by the SMOS Barcelona Expert Center

The SMOS-BEC researchers contribute to the ESA mission as Expert Support Laboratory for L1 (UPC) and L2-salinity (ICM). Besides analysing and proposing solutions to the various aspects of the data processing at all levels that still require improvement $[3,4]$, the SMOS-BEC team is studying 
for example alternative image reconstruction or salinity retrieval approaches, and possible new products for the CP34, as well as preparing the exploitation of SMOS data, like their assimilation into ocean circulation numerical models. Although it was not one of its primary focuses, the group is also addressing the analysis of SMOS data over land and investigating new methodologies to add value to the original SMOS products. Some of the experimental maps built by SMOS-BEC, as well as Cartesian versions of the CP34 operational products are also accessible to the research community through the SMOS-BEC distribution service at http://tarod.cmima.csic.es/.

\section{SOIL MOISTURE AND OCEAN SALINITY MAPS}

Sea surface salinity (SSS) maps are operationally generated at CP34 (Fig. 2) for periods of 3, 10 and 30 days at the original spatial resolution or by binning SMOS L2 data in boxes of $1^{\circ} \times 1^{\circ}$, and also by using an optimal interpolation (OI) method of the anomalies by respect the World Ocean Atlas SSS fields $[5,6]$. The main objective for these SMOS L3 SSS maps is to reduce the high level of noise present in the original L2 products due to the low sensitivity of the brightness temperature recorded by MIRAS to SSS and the uncertainties associated to the salinity retrieval process [7]. At the SMOSBEC, current efforts on L3 are focused on improving the application of OI analysis on L2 data to produce L3 maps with greater accuracy and interpolated into data gaps. An accurate filtering of low quality L2 values is essential to accomplish this objective.

Sea Surface Salinity

$1^{\circ} \times 1^{\circ}$ L2 binned map - $21 / 23$ February, $2012-$ CP 34 produc

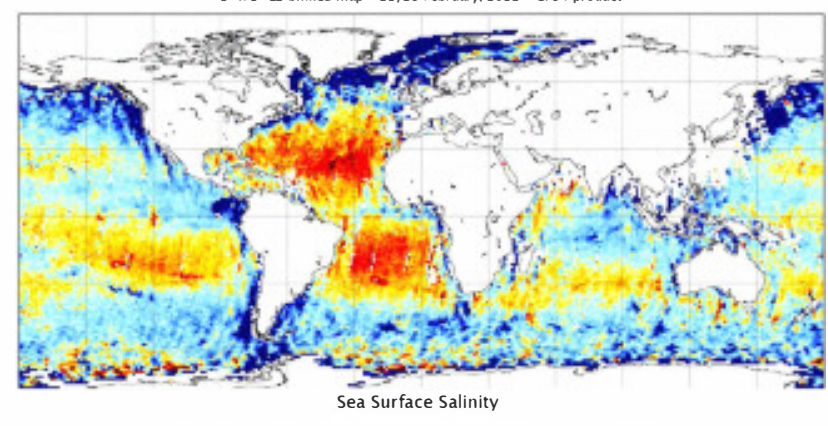

$1^{\circ} \times 1^{\circ}$ Optimal Interpolated map - 22 January/ 21 February. 2012 - CP34 product

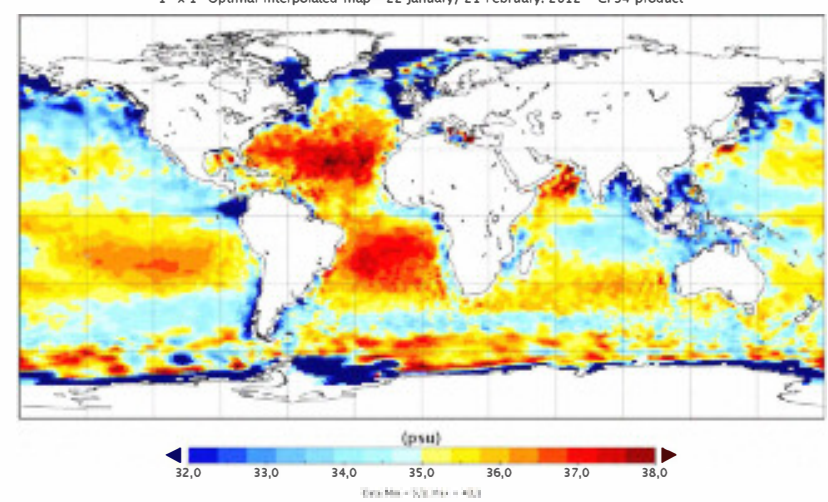

Figure 2. SMOS sea surface salinity $1^{\circ} \times 1^{\circ}$ maps operationally generated at CP34: top) 3-days binned average for 21-23 February 2012; bottom) 30-days optimal interpolation for 22 January-21 February 2012
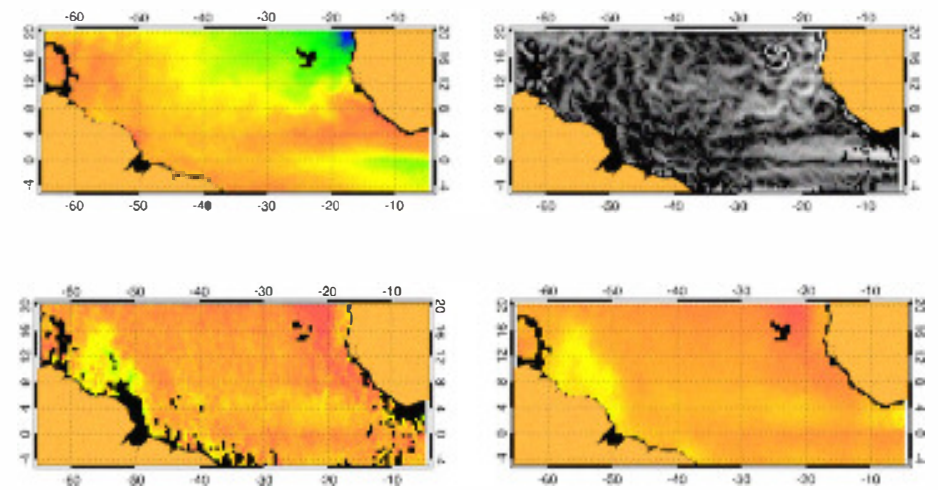

Figure 3. Top left) AMSR-E SST image of the region of the Amazon plume in the tropical Atlantic ocean; top right) singularity exponents extracted from the SST image; bottom left) contemporaneous 10-days binned SMOS SSS L3 map of the same region; bottom right) reconstructed SMOS SSS L4 map built

by fusing the singularity structures obtained from SST into the SSS L3.

Ongoing work at SMOS-BEC on L4 production aims at the development of data fusion techniques to combine the SMOS data with other satellite observations (e.g., AMSR-E sea surface temperature (SST), surface chlorophyll concentration or Aquarius SSS data). The technique is based on the use of singularity analysis, to exploit data synergy [8]. The information provided by singularity exponents is then used to reconstruct improved SSS fields satisfying the multi-scale characteristics of geophysical flows (Fig. 3).

The SMOS L3 and L4 SSS maps are being validated with near-surface measurements provided by the Argo operational array of temperature and salinity profilers (more than 3000 across the world oceans), which allow defining several quality metrics. Despite SMOS is sampling the first centimeter of the ocean and the Argo profiles don't reach the upper few meters, in most of the ocean regions the measured salinity is expected to be very similar. Depending on the periods analyzed, and of course on the type of maps, the SMOS-Argo $\triangle$ SSS displays a global standard deviation of few tenths of practical salinity units. This is an order of magnitude better than the uncertainty of the L2 products, but still has to be improved to reach the mission requirements (mainly in the radiometric calibration and image reconstruction steps at $\mathrm{L} 1$, the salinity retrieval algorithm, and also in the L2 data selection to build L3 maps).

The CP34 land products are maps of the soil moisture, vegetation water content, soil roughness and real and imaginary parts of the dielectric constant, with the maximum spatial resolution (ISEA4H9 grid) for several temporal windows and generated at different time steps. Unlike the case of ocean products, the objective here is not reducing noise but reaching a maximum spatial coverage while keeping the spatial resolution. Although MIRAS measurements are much more robust with respect to soil moisture variability than to ocean salinity, the main problem for land products is the need of different retrieval algorithms for the different soil types. At present there are large areas where soil moisture cannot be determined, namely in frozen soils or with important snow accumulation, regions of abrupt topography and soil under thick vegetation cover like tropical forests (see Fig. 4). 
Soil Moisture

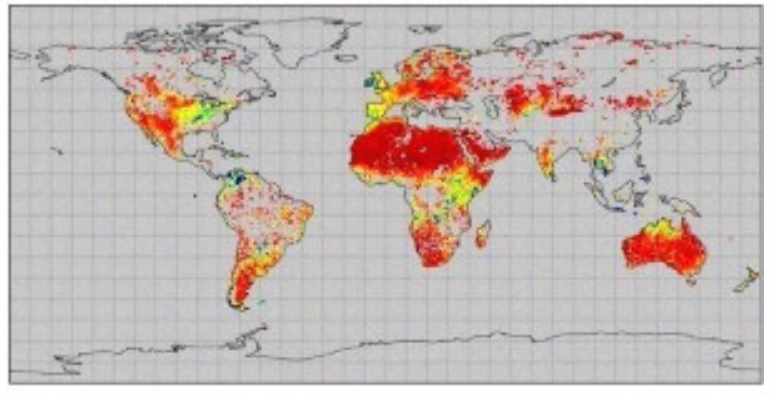

4 Soll Moisture $(\mathrm{mz} / \mathrm{mm})$

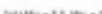

Vegetation Water Conten

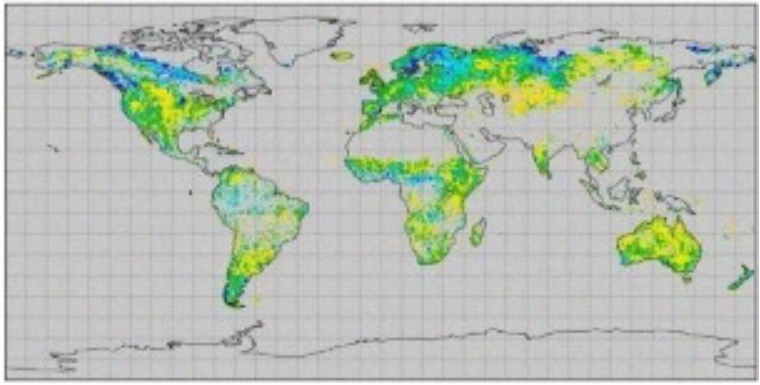

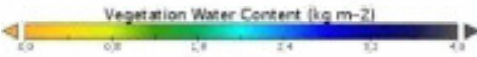

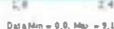

Real part of Dielectric Constant

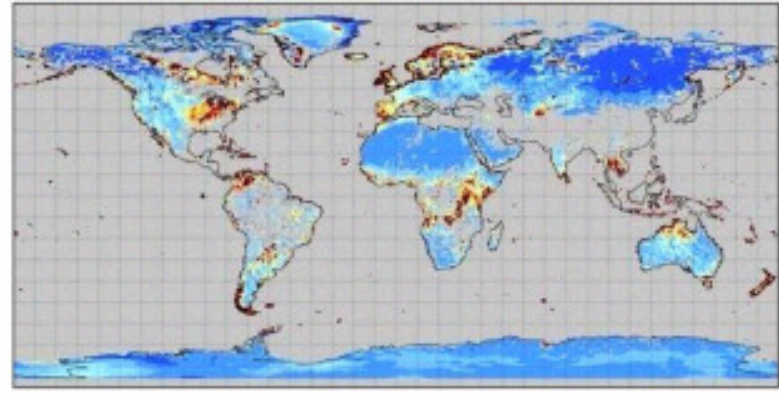

Real part of Dielectric Constant of $m-1$

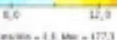

Imaginary part of Dielectric Constant

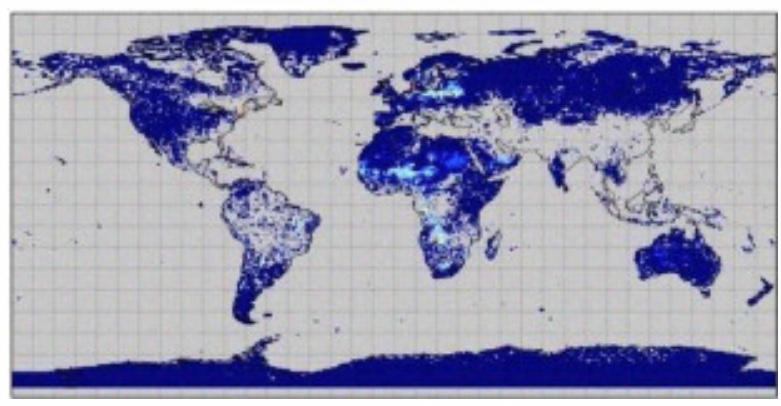

Imaginary part of Dielectric Consars if $m=1$ ) is 45

Figure 4. SMOS L3 land products operationally generated at CP34 for the period 11-20 November 2011. From top to bottom: soil moisture, vegetation water content, and real and imaginary parts of the dielectric constant
For land applications, SMOS spatial resolution is adequate for improving our understanding of water and energy fluxes between the atmosphere, the soil surface, and subsurface. However, it is insufficient for regional applications, such as land and water resources management, agricultural productivity, weather and climate forecasting, and flood and drought mitigation, which require a spatial resolution of 1 to 10 $\mathrm{km}$. At the SMOS-BEC, a downscaling algorithm that combines SMOS radiometric estimates with MODIS visible and infrared satellite data has been implemented to generate 1 $\mathrm{km}$ soil moisture maps.

The algorithm was first applied to a set of SMOS images acquired during the commissioning phase over South-Eastern Australia. Results from comparison with ground-based soil moisture measurements showed that soil moisture variability is effectively captured at 10 and $1 \mathrm{~km}$ spatial scales, without a significant degradation of the root mean square error [9]. This downscaling approach is now being applied to different regions so as to evaluate the performance of the algorithm over a wide variety of land covers and climate conditions (Fig. 5). Likewise, its validation at an intermediate resolution over the REMEDHUS soil moisture monitoring network [10] in Salamanca, Spain, using airborne L-band, Thermal and VNIR hyperspectral observations is underway.
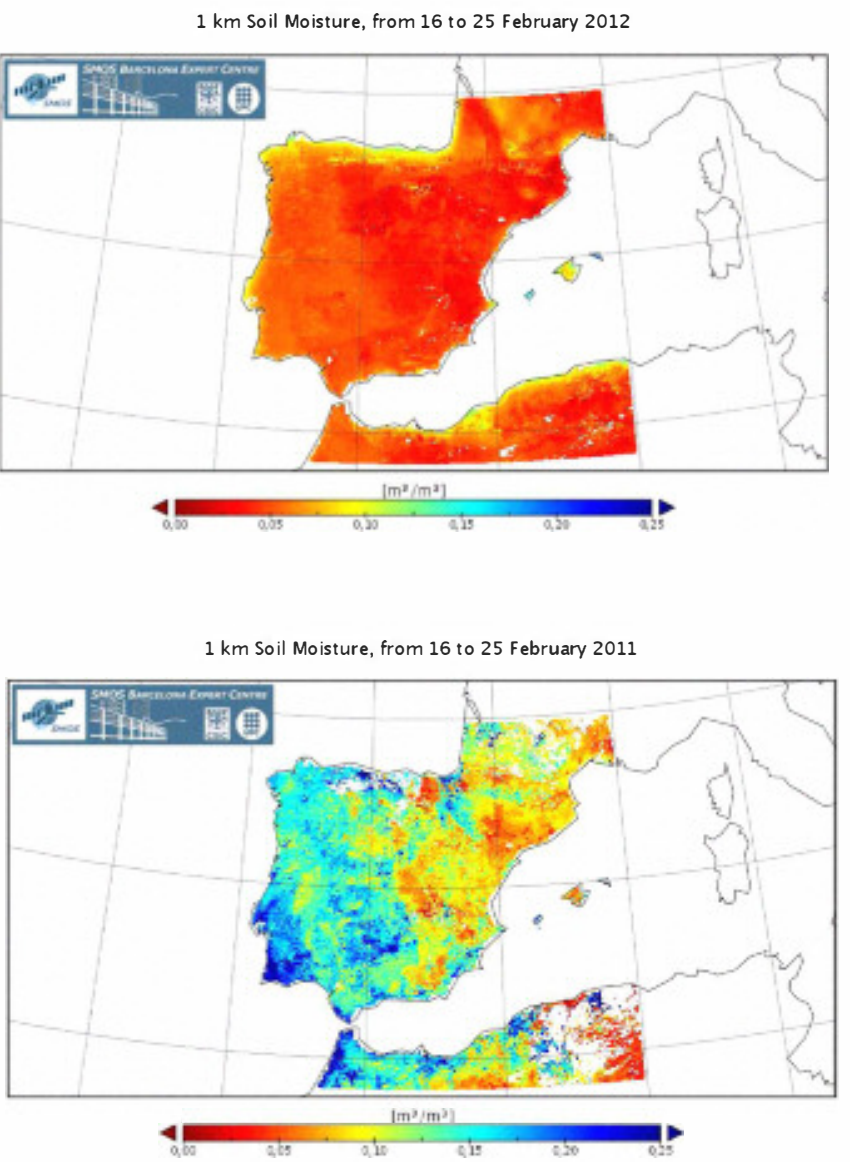

Figure 5. Examples of high resolution $(1 \mathrm{~km})$ soil moisture maps of the Iberian peninsula generated from SMOS data (10 days average) at SMOSBEC: top) 16-25 February 2012, under very dry conditions; bottom) same period in 2011, when winter rainfall had been closer to cimatology. 
The image on the top of Fig. 5 is from February 2012 within an extreme drought period suffered by Southwestern Europe since November 2011. For comparison, the map that corresponds to the same period in 2011 is shown on the bottom of Fig. 5. Experimental high resolution soil moisture maps over the Iberian Peninsula are already available at the SMOS-BEC web server (http://tarod.cmima.csic.es/). Information on soil moisture at a spatial resolution of the order of $1 \mathrm{~km}$ allows its use in applications like evaluation of soil water content for agriculture management. Another application, important under conditions of extreme drought, is its ability to identify specific areas with high risk of fire by combining the knowledge of soil moisture with forecasts of air temperature and wind intensity.

\section{ACKNOWLEDGMENT}

This work has been possible thanks to the many research, institutional and industrial teams worldwide that made possible the design, implementation and operation of the SMOS mission. Support from the Spanish delegation to ESA CDTI, National R\&D\&I Plan, CSIC and UPC authorities has been fundamental for the success of SMOS-BEC and CP34 activities.

\section{REFERENCES}

[1] Y.H. Kerr, P. Waldteufel, J.P. Wigneron, S. Delwart, F. Cabot, J. Boutin, M.J. Escorihuela, J. Font, N. Reul, C. Gruhier, S. Juglea, M.R. Drinkwater, A. Hahne, M. Martín-Neira, and S. Mecklenburg, "The SMOS mission: New tool for monitoring key elements of the global water cycle", P. IEEE, vol. 98, pp. 666-687, 2010.

[2] J. Font, A. Camps, A. Borges, M. Martín-Neira, J. Boutin, N. Reul, Y.H. Kerr, A. Hahne, and S. Mecklenburg, "SMOS: The challenging sea surface salinity measurement from space", $P$. IEEE, vol. 98, pp. 649$665,2010$.

[3] S. Mecklenburg, M. Drusch, Y.H. Kerr, J. Font, M. Martin-Neira, S. Delwart, G. Buenadicha, N. Reul, E. Daganzo-Eusebio, R. Oliva, R. Crapolicchio, "ESA's Soil Moisture and Ocean Salinity mission: mission performance and operations," IEEE T Geosci Remote, in press, 2012.

[4] J. Font, J. Boutin, N. Reul, P. Spurgeon, J. Ballabrera-Poy, A. Chuprin, C. Gabarró, J. Gourrion, C. Hénocq, S. Lavender, N. Martin, J. Martínez, M. McCulloch, I. Meirold-Mautner, C. Mugérin, F. Petitcolin, M. Portabella, R. Sabia, M. Talone, J. Tenerelli, A. Turiel, J.L. Vergely, P. Waldteufel, X. Yin, S. Zine, and S. Delwart, "SMOS first data analysis for sea surface salinity determination", Int. J. Rem. Sens., in press, 2012.

[5] J.I. Antonov, D. Seidov, T.P. Boyer, R.A. Locarnini, A.V. Mishonov, H.E. Garcia, O.K. Baranova, M.M. Zweng, and D.R. Johnson, "World Ocean Atlas 2009, Volume 2: Salinity," in NOAA Atlas NESDIS 69, S. Levitus, Ed. U.S. Government Printing Office, Washington, D.C., 184 pp.

[6] G. Jordà, D. Gomis, and M. Talone, "The SMOS L3 mapping algorithm for sea surface salinity," IEEE T Geosci Remote, vol. 49, pp. 1032 1051, Mar 2011.

[7] S. Zine, J. Boutin, J. Font, N. Reul, P. Waldteufel, C. Gabarró, J. Tenerelli, F. Petitcolin, J. L. Vergely, M. Talone, and S. Delwart, "Overview of the SMOS sea surface salinity prototype processor," IEEE T. Geosci. Remote, vol. 46, pp. 621-645, Mar 2008.

[8] A. Turiel, V. Nieves, E. Garcia-Ladona, J. Font, M.H. Rio, and G. Larnicol, "The multifractal structure of satellite sea surface temperature maps can be used to obtain global maps of streamlines," Ocean Sci., vol. 5. pp. 447-460, 2009

[9] M. Piles, A. Camps, M. Vall-llossera, I. Corbella, R. Panciera, C. Rudiger, Y.H. Kerr, and J. Walker, "Downscaling SMOS-derived soil moisture using MODIS visible/infrared data," IEEE T Geosci Remote, vol. 49, pp. 352-374, Sept. 2011.

[10] N. Sánchez, J. Martínez-Fernández, A. Scaini, and C. Pérez-Gutiérrez, "Validation of the SMOS L2 soil moisture data in REMEDHUS network (Spain)," IEEE T Geosci Remote, in press, 2012. 